\title{
Sustainability as a basic property of the phenomenon of life organized in supraorganismal systems
}

\author{
Alexander Nikol'skii, ${ }^{*}$ Konstantin Belovezhets, and Elena Vanisova \\ Peoples' Friendship University of Russia (RUDN University), Faculty of Ecology, 6 Miklukho- \\ Maklaya St, Moscow, 117198, Russian Federation
}

\begin{abstract}
The phenomenon of life is organized in supraorganismal systems, populations and ecosystems. The main mechanisms of sustainability of these systems are: 1) the influence of limiting factors on population growth and ecosystem development; 2) the allocation of plant and animal species into ecological niches; 3) co-adaptation of plants and animals; 4) species genetic integration; 5) biocommunications. Limiting factors inhibit populations' growth and distribution of organisms, so that populations obey the logistic growth, reaching a relatively stable climax stage. The space of limiting factors restricted by the tolerance limits of organisms forms an ecological niche of species. During long-joint evolution (co-evolution), species form co-adaptations (mutual adaptations). As a result of species genetic integrity, each new generation inherits not only adaptations for its specific ecological niche, but also a determined physical space including all the environmental factors to which the species is adapted. Consolidation of individuals with a related genotype is supported by intraspecific communication processes. Means of communication are genetically determined. Humankind is the only species on Earth that has subjugated limiting factors. As a result the population of humans shows an unlimited exponential growth, population explosion. It is a basic factor in the instability of the Nature - Society system.
\end{abstract}

\section{Introduction}

Resolution of the United Nations [1] "Transforming our world: the 2030 Agenda for Sustainable Development" adopted by the General Assembly in 2015 calls the world community to the sustainable development without explaining what is to be developed sustainably. And only from the context of this document it is possible to understand that the sustainability of the system "Nature - Society" is discussed.

Sustainability is a natural state of the phenomenon of life organized in supraorganismal systems (populations and ecosystems) of different levels. The purpose of our report is to discuss some mechanisms of the sustainability of supraorganismal systems. Due to metabolism and interactions in ecosystems, plants and animals are sustainably using the energy of the Sun that comes to Earth over millions of years.

*Corresponding author: bobak@list.ru 
German agricultural chemist Justus von Liebig was the first to justify the stability of supraorganismal systems, 25 years before another great German, Ernst Haeckel, uttered the word "ecology" [2]. Considering the atmosphere as the habitat of organisms, Liebig emphasized that this habitat was created by the organisms themselves and maintained by them in a stable condition [3, p. 21]: "Plants not only afford the means of nutrition for the growth and continuance of animal organization, but they likewise furnish that which is essential for the support of the important vital process of respiration; for besides separating all noxious matters from the atmosphere, they are an inexhaustible source of pure oxygen, which supplies the loss which the air is constantly sustaining. Animals on the other hand expire carbon, which plants inspire; and thus the composition of the medium in which both exit (italics are ours), namely, the atmosphere, is maintained constantly unchanged".

Ecology, the science of the structure and functioning of supraorganismal systems [4], clearly indicates the basic mechanisms of stability of the phenomenon of life, such as, in particular: 1) limiting factors, 2) distribution of species and populations into ecological niches, 3) coadaptations, 4) genetic integration of species; 5) intraspecific and interspecific communicative processes. And it also clearly indicates the role of humankind in the destruction of mechanisms of sustainability.

Further, on the results of our own studies published earlier, and on the results of studies of other authors, we discuss the main mechanisms of sustainability of the phenomenon of life organized in populations and ecosystems.

\section{Main}

\subsection{Limiting factors}

The key idea of ecology is the concept of limiting factors, a mechanism that restrains population growth and expansion of plants and animals. The concept of limiting factors explains the fundamental difference between the dynamics of the population of humans and the dynamics of the populations of other organisms' species. Fig. 1 illustrates this idea, showing that populations of plants and animals have a pattern of logistic growth. Having reached the limit of growth in certain environmental conditions, the population remains in this relatively (wavy line) stable state of abundance and productivity for an unlimited time. And, on the contrary, humankind, controlling the limiting factors and having subordinated resources to itself, thereby created the conditions for unlimited, exponential population growth, deprived of a relatively stable stage.

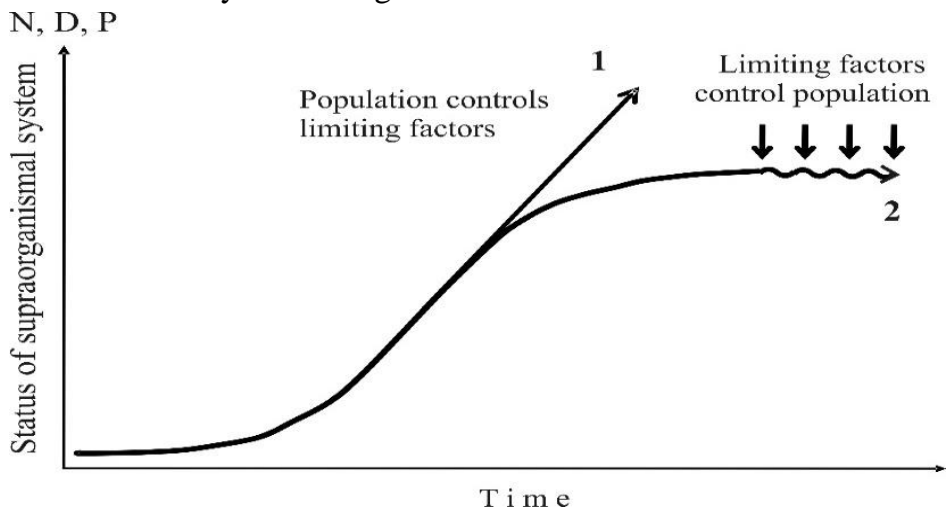

Fig. 1. Development patterns of supraorganismal systems. Growth of human population (1) and other species of organisms (2). $\mathrm{N}$ - population size, $\mathrm{P}$ - productivity of population/ecosystem. $\mathrm{D}$ - species diversity of ecosystem. 
The idea of limiting factors can easily be extrapolated from populations to ecosystems, which in addition to abundance and productivity are also characterized by species diversity, and the limit of growth is associated with a relatively stable stage of climax. Eugene Odum [5] paid attention to it, emphasizing that in general the status of ecosystems is determined by the flow of energy coming from the Sun, which is clearly illustrated on the example of zonal ecosystems. Indeed, for many millions of years, rainforests near the equator remain rainforests, with their huge biological productivity and almost unlimited species diversity and, for example, tundra at high latitudes remains tundra, with its poor productivity and a limited number of plant and animal species.

The main contribution to the development of the idea of limiting factors was made at the beginning of the last century by J. Johnstone, V. Shelford, A. Tinemann, I.K. Pachosky, and G.F. Gause [6-10].

An outstanding role in comprehension of the mechanisms of population growth was played by the equation of the Belgian demographer Pierre Verhulst [11], rediscovered at the beginning of the 20th century by American scientist Raymond Pearl [12]:

$$
\frac{d N}{d t}=\frac{b N(K-N)}{K}
$$

where $K$ is the maximum possible population size, $N$ is the population size at time $t, b$ is a reproduction coefficient (proportionality coefficient).

When $N=K$ the growth stops, and the populations enter an equilibrium state. In this relatively stable condition they can be for an unlimited time.

Logistical, or "Verhulst", curve depicted in Fig. 1:2 shows the future of a population or an ecosystem restricted by limiting factors. For the ecosystem, the main limiting factor is the energy of the Sun. After reaching the climax stage, the ecosystem remains at this level of productivity and species diversity until the flow of energy coming from the Sun changes [5]. Due to the fact that humankind controls the limiting factors, its population grows exponentially to infinity (Fig. 1).

\subsection{Distribution of species and populations into ecological niches}

A population of any species of plants and animals is relatively stable exactly because it is restricted by limiting factors that together form an ecological niche - hypervolume, or multidimensional space of factors $[13,14]$. The tolerance range for each of the factors and, what is not less important, for their combined effect ("the effect of constellation" [15]) "locks" the population within the limits of the ecological niche. Eurybiontism of organisms is not absolute and has its limitations. The prefix "eury", being understood literally, is sometimes misleading. Only humans could spread across the entire surface of our planet by controlling of the limiting factors.

\subsection{Coadaptations}

The stability of supraorganismal systems is also indicated by such a ubiquitous phenomenon as coadaptations or mutual adaptations. A mutual adaptation of insects and pollinated plants is a good example. Coadaptations are the result of coevolution. Evolution is a long process. Therefore, a stable condition of the species composition of the subjects of the coevolutionary process is necessary in order for coadaptation to take place. That is why on the evolutionary time scales the species structure of ecosystems cannot change too quickly. 


\subsection{Genetic integration of species}

A huge influence on the stability of supraorganismal systems is exerted by the genetic integration of species, regulated by the flow of genes [16]. Each new generation inherits not only a complex of adaptations that allows it to assimilate the ecological niche peculiar to the species, but also, at the place of birth, a certain physical space with all the limiting factors to which the species is adapted.

\subsection{Intraspecific and interspecific communicative processes}

Consolidation of individuals with an affined genotype is facilitated by intraspecific communicative processes. The species specificity of the communicative means, for example sound signals, corresponds to the genotype. So the phonotype, which is the complex of features of the sound signal, specific for the species, corresponds to the genotype. In early bioacoustic studies the species specificity of sound signals was already shown in various groups of vertebrate and invertebrate animals [17].

Fig. 2 shows, as an example of the correspondence between the phonotype and the genotype, cluster diagrams of the characteristics of alarm call, as well as nuclear and mitochondrial DNA of 7 species of marmots.

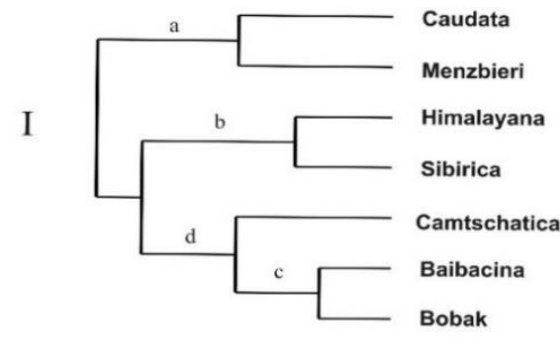

(a)
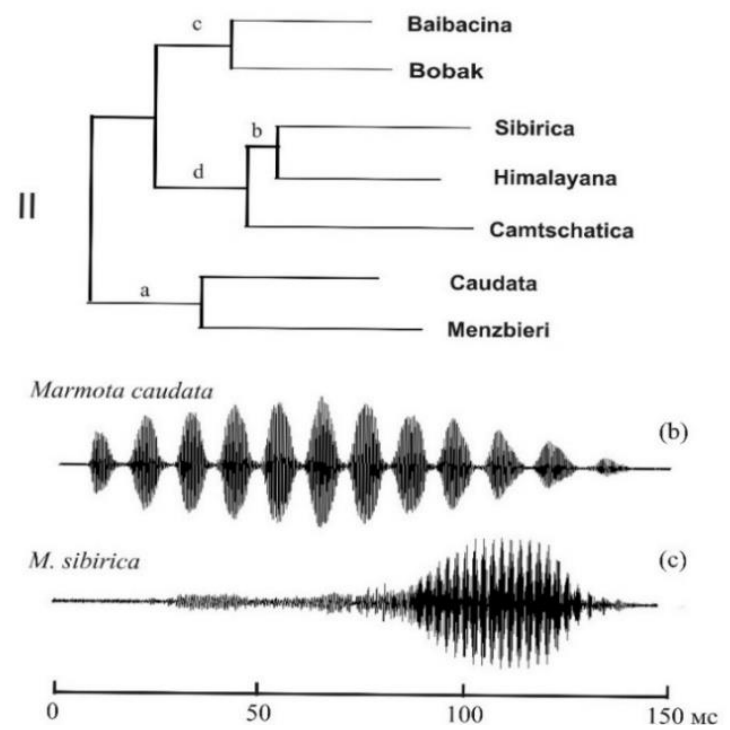

Fig. 2. Correspondence of the phonotype to the genotype. (a) - dendrogram of the sound signal characteristic of marmots (I, according to [18]) and mitochondrial and nuclear DNA (II, according to [19]); a, d, c, d-clusters; oscillograms of the alarm call of Red (b) and Mongolian (c) marmots are an example of the species-specific characteristics of the signal. 
As it can be seen from the Fig. 2, the distribution by species on both dendrograms coincides. The number of clusters coincides too. The difference is only in the position of the black-caped marmot (Marmota camtschatica). It falls into different clusters at the dendrograms, which is quite explainable by its huge and strongly torn range [20], within which significant intraspecific differences are possible. It is possible that these differences reach an interspecific level.

A special case of biocommunications is a biological signal field. It also supports the stability of supraorganismal systems. The biological signal field represents the traces of vital activities left by each generation of animals. These traces of vital activities create an odorvisual image of the territory, forming a matrix of stable elements, so that each new generation reads information from it [21-24]. As a result of such ecological inheritance [25], information about the territory with the resources located on it, is sustainably transmitted from generation to generation.

Fig. 3 shows an example of a matrix of stable elements in the biological signal field. On the family site of the steppe marmots $(M$. bobak), which is shown there, the matrix of stable elements that organizes the trajectory of animals moving around the territory is formed by paths and burrows. Both of them are updated and steadily used from generation to generation for a very long time, up to many thousands of years [26].

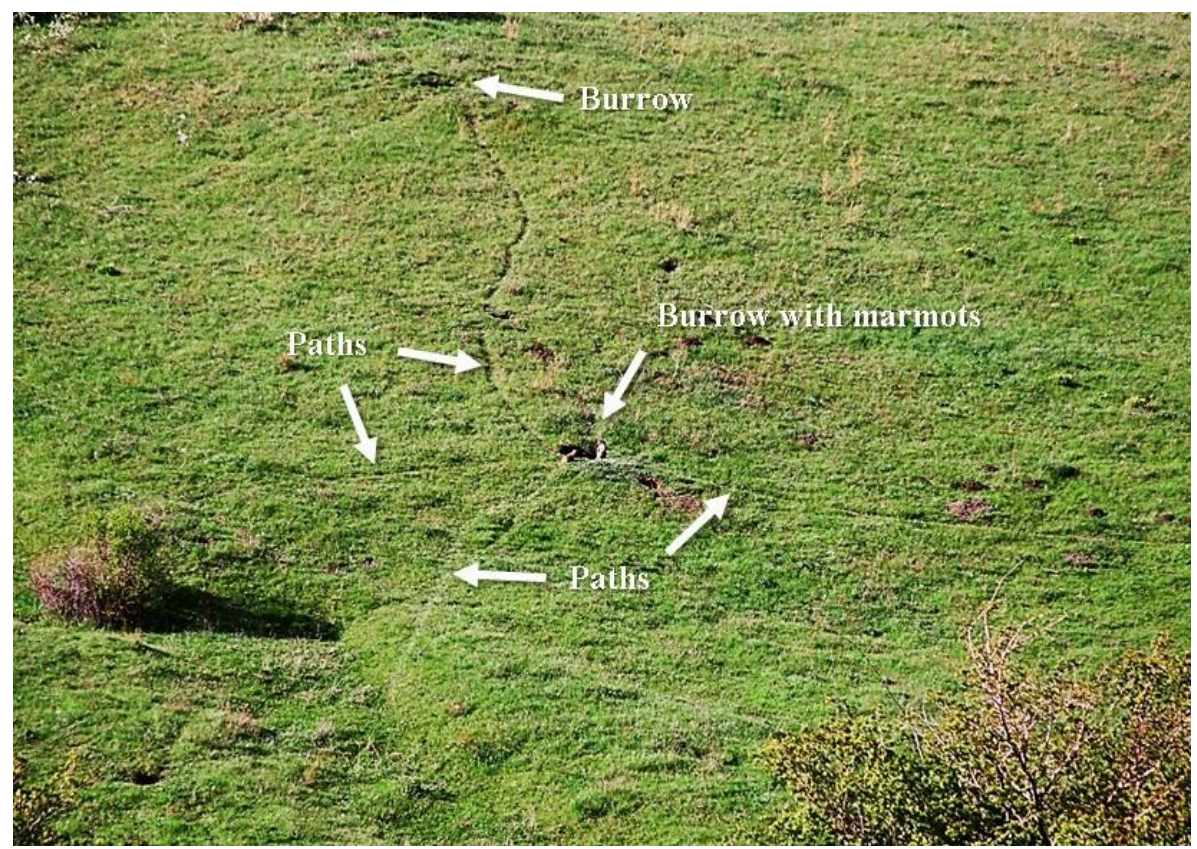

Fig. 3. Example of a matrix of stable elements of the biological signal field is the territory of a marmot family. Traces of vital activities (burrows and paths), transmitted from generation to generation, create a visual (and image of space, organizing the trajectory of the movement of animals through the territory with resources on it.

The biological signal field formed by a multi-species community supports the sustainability of ecosystems, facilitated by interspecific communicative processes.

\section{Conclusion}

At the beginning of our report, we drew attention to the fact that humanity controls the limiting factors, including resources in the traditional sense of the word, for example, food 
resources. The earliest forms of farming and cattle breeding appeared about 12 to 8 thousand years ago [27, 28]. Many thousands of years ago [29] the first power engineers created the first power plant, a fire, subjugating the most important of the limiting factors, the temperature. In fact, the fire was the first alternative energy source, the alternative to the Sun. After mastering the fire, clothes and dwellings, people started to control temperature, the limiting factor that restricts ranges of absolutely all species of plants and animals.

Today, there are about 7.5 billion of us on the Earth, and nothing holds back the further increase in the number of people. But in the UN Resolution on Sustainable Development [1] nothing is said about the demographic explosion that destroys the biosphere: in this heterogeneous international organization, it is not easy to discuss sensitive issues of demography.

We find an in-depth analysis of the demographic explosion problem, a politically sustained and delicately formulated solution to it, from academician V.M. Kotlyakov in his remarkable work "Geography in a Changing World" [30]. Kotlyakov offers the only possible way for the sustainable development of the "Nature - Society" system [30, p. 345-346]: “... Comprehensive approaches show the need for a revision of the value system that guides mankind ... The traditional fear of depopulation and political incentives for the prestige of large families are associated with the inevitable in the past loss of competitiveness of the nation reducing the population. This danger disappears during the transition to a proportional reduction in the number of all nations (while maintaining the populations of small nations). Recently, the prestige of large families has been rapidly declining throughout the world, and humanity is getting closer to the moral realization of the possibility of transition to one-child birth. Thus, the opportunity under consideration is real from an economic, demographic, environmental, and moral and ethical point of view."

In conclusion, we would like to draw attention to the importance of systematizing the knowledge accumulated in archeology over the past 200 years on the history of the exemption of Homo sapiens from limiting factors, as an independent section of human ecology, which will contribute to a better understanding of the role of human in the future of our planet.

\section{References}

1. Resolution adopted by the General Assembly on 25 September 2015" Transforming our world: the 2030 Agenda for Sustainable Development". URL: https://www.un.org/ga/search/view_doc.asp?symbol=A/RES/70/1\&Lang=E

2. E. Haeckel, Generelle Morphologie der Organismen. Bd. 1, 2 (Berlin: Verlag von Georg Reimer, 1866)

3. J. Liebig, Organic chemistry in its applications to agriculture and physiology (L.: Taylor and Walton, 1840)

4. N.P. Naumov, Zh. Obshch. Biol., 32(6), 651-666. (1971)

5. E. Odum, Fundamentals of Ecology (WB Saunders, Philadelphia, 1971)

6. J. Johnstone, Conditions of life in the sea. A short account of quantitative marine biological research (Cambridge: The University Press, 1908)

7. V.E. Shelford, Biol. bulletin, 25(2), 79-120 (1913)

8. A. Thienemann, Das Leben im Süßwasser (Breslau: Ferdinand Hirt, 1926)

9. I.K. Pachosky, Fundamentals of Phytosociology. The course, taught at the Agronomy Faculty of the Polytechnic Institute (Kherson: Studencheskii komitet Sel'skkhoztekhnikuma, 1921) (in Russian)

10. G.F. Gause, The Struggle for Existence (Baltimore: The Williams and Wilkins Company, 1934) 
11. P.F. Verhulst, Mémoires de l'Académie Royole des Belgique, 18(1), 1-38 (1845) (Citation: Hutchinson, 1978).

12. R. Pearl, L.J. Reed, Proceedings of the National Academy of Sciences, 6(6), 275-288 (1920):

13. G.E. Hutchinson, Cold Spring Harbor Symposia on Quantitative Biology, 22(2), 415427 (1957)

14. G.E. Hutchinson, An Introduction to Population Ecology (New Haven, L.: Yale Univ. Press, 1978)

15. S.S. Schwartz, Current problems of ecology: Fifth All-Union Ecological Conf., 21-31 (Moscow: Mosk. Gos. Univ., 1973) (in Russian)

16. E. Mayr, Animal species and evolution (Oxford Univ. Press, London,, 1963)

17. Acoustic behaviour of animals (R.-G. Busnel, ed., Elsevier, Amsterdam, 1963)

18. A.A. Nikol'skii, Russian Journal of Zoology, 93(8), 1026-1043 (2014) (in Russian)

19. S.J. Steppan, G.J. Kenagy, Ch. Zawadzki, R. Robles, E.A. Lyapunova, R.S. Hoffmann, J. of Mammalogy, 92(5), 1028-1037 (2011)

20. I.M. Gromov, D.I. Bibikov, I.I. Kalabukhov, M.N. Meier, Fauna of the USSR. Mammals. T. III. Vyp.2. Terrestrial Sciurids (Marmotinae) (Moskva, Leningrad: Nauka, 1965) (in Russian)

21. N.P. Naumov, Development of the concept of structural levels in biology, 322-331 (Moscow: Nauka, 1972):. (in Russian)

22. N.P. Naumov 1973. Current problems of ecology: Fifth All-Union Ecological Conf., 3-20, (Moscow: Mosk. Gos. Univ., 1973) (in Russian)

23. N.P. Naumov, M.E. Gol'tsman, E.P. Kruchenkova, N.G. Ovsyanikov, S.V. Popov, V.M. Smirin, Theriology issues. Ecology, Population Structure and Intraspecific Communications between Mammals, 31-75 (Moscow: Nauka, 1981) (in Russian)

24. E.A. Vanisova, A.A. Nikol'skii, Biology Bulletin Reviews, 3(5), 335-346, (2013)

25. A.A. Nikol'skii, Russian J. of Ecology, 45(1), 76-79, (2014)

26. Yu.A. Dubrovskii, The study of the geography of natural resources of the animal and plant world (For 60th Anniversary of A.N. Formozov), 80-94 (Moscow: USSR Academy of Sciences, 1962). (in Russian)

27. Agriculture: Manual G.I. Bazdyrev ed. (Moscow: INFRA, 2013), 608 p. [in Russian]

28. N.V. Grikhina, I.A. Sorokina, History of zootechnical science: manual (Michurinsk: Michurinskii GAU, 2019) (in Russian)

29. R. Shahack-Gross, F. Berna, P. Karkanas, C. Lemorini, A. Gopher, R. Barkai, J. of Archaeological Science, 44, 1 (2014): 12-21.

30. V.M. Kotlyakov, Selected Works in Six Books. Book 3. Geography in a changing world (Moscow: Nauka, 2001) (in Russian) 